\title{
Objectos egípcios nas reservas do Museu Calouste Gulbenkian
}

\author{
Luís Manuel de ARAÚjO
}

O Museu Calouste Gulbenkian, em Lisboa, possui uma bela colecção egípcia que é bem conhecida nos meios egiptológicos, estando expostas quarenta peças. No entanto, fazem parte do acervo reunido por Calouste Gulbenkian mais catorze peças que estão nas reservas do Museu, sendo algumas de origem duvidosa. No novo catálogo da colecção que está a ser elaborado prevê-se a publicação dos objectos das reservas, que até agora se têm mantido inéditos. Antecipando a publicação, que terá um carácter mais detalhado, aqui se apresentam sumariamente os referidos objectos.

\section{Egyptian objects in the reserve collections of the Calouste Gulbenkian Museum}

The Calouste Gulbenkian Museum, in Lisbon, has a fine Egyptian collection which is well known in the Egyptological field. Fourty pieces are exhibited in a refurbished room. However, within the collection gathered by Calouste Gulbenkian, there are another fourteen items, presently in the museum's store, some of which are of doubtful origin. The new catalogue of the collection, currently in preparation [September 2006], will detail these previously unpublished objects. Anticipating this publication, a brief description is given here of a bowl, five panels from a casket, a bronze lion, a scarab, two funerary statuettes, two bronze statuettes and two limestone statues of officials.

Key words: Ancient Kingdom, 26th Dynasty, Ptolemaic and Roman Periods, MacGregor and Rothermere Collections, Howard Carter

Tigela

Alabastro

Império Antigo (?), III dinastia (?) (c. 27002600 a. C.)

Alt.: 3,8 cm; Diâm.: $5 \mathrm{~cm}$

Proveniência: Colecção MacGregor

Data de incorporação: 1922

$\mathrm{N}^{\mathrm{o}}$ inv.: $409 \mathrm{~B}$

Recipiente restaurado apresentando muitas fracturas, de paredes direitas, que vão estreitando para a base de fundo plano. O estilo deste recipiente é comum entre os vários objectos do Império Antigo, e aparece com frequência nos espólios tumulares com diferentes formas.

Fecha de recepción: 19 de enero de 2007
Os registos da colecção sugerem que esta tigela faria um conjunto com a taça de alabastro (cat. $\mathrm{n}^{\mathrm{o}} 1$ ), mas observando as duas peças vê-se não ser possível a harmonização da taça com a tigela. Por um lado, falta à tigela a translucidez e a delicadeza do trabalho que se detecta na taça, por outro não se conhecem conjuntos de duas peças neste tipo de baixela do Império Antigo.

\section{Painéis de um Cofre}

Marfim

Época Baixa, XXVI dinastia (?)

Dimensões variadas

Proveniência: Colecção MacGregor

Data de incorporação: 1922

$\mathrm{N}^{\mathrm{o}}$ inv.: $164 \mathrm{C}$ a $164 \mathrm{G}$

Fecha de admisión: 15 de mayo de 2007 


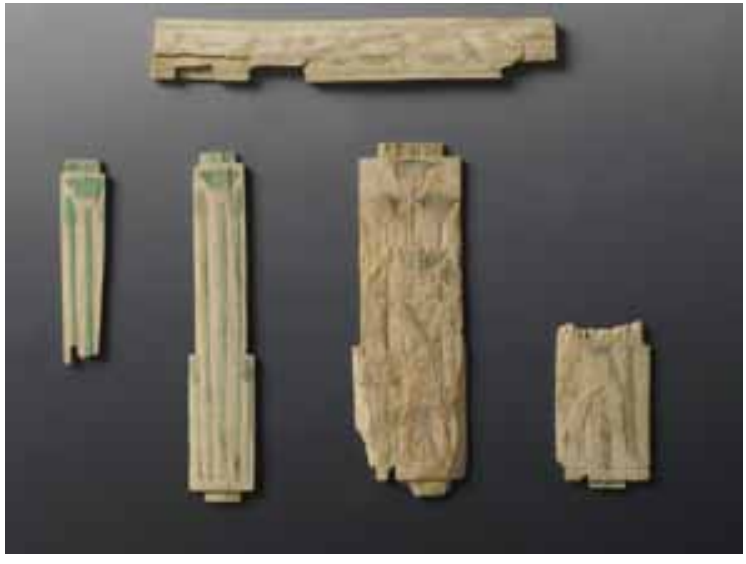

Trabalhados em fino baixo-relevo, estes painéis, e outros que com ele revestiam um pequeno contentor, são considerados como sendo dos mais belos trabalhos egípcios executados em marfim. Decoravam um cofre ou uma caixa para jóias, sendo o primeiro fragmento (164 C) diferente porque não só está na horizontal, ao contrário dos restantes que estão na vertical, como também exibe uma inscrição hieroglífica. $\mathrm{O}$ texto foi gravado com belos hieróglifos que certamente seriam pintados de verde, a avaliar pelos vestígios de cor ainda presentes nos outros fragmentos. Duas linhas feitas em relevo delimitam, em cima e em baixo, o curto texto, que está dividido em duas partes, embora ao meio não exista nenhum traço separador - a separação é feita pela expressão $i r . k$ (forma verbal do verbo «fazer»). Uma parte do texto corre da esquerda para a direita e outra da direita para a esquerda, a partir da forma $i r . k$ que se repete ao meio.

[68 ]

Texto da direita para a esquerda: «Faz o que o teu coração deseja...»

Texto da esquerda para a direita: «Faz o que desejas e não te preocupes»

O curto texto duplo da pequena placa é um apelo à fruição dos prazeres da vida, de acordo com os desejos do coração do homem, em que avulta o amor e o pleno gozo dos prazeres na companhia da mulher amada. Faz lembrar as exortações dos «cantos de harpista», em que se enaltece a vida e deplora a chegada da morte. O que interessava, acima de tudo, era gozar uma vivência terrena em plenitude e o canto bem o diz: «Segue o teu coração todo o tempo que viveres!»

Nesta ambiência idílica e de timbre erotizante se insere a produção de objectos destinados aos preparativos do encontro amoroso, o que justifica a intensa produção de adornos e de objectos de toucador como "colheres» para cosméticos. O pequeno cofre ou caixa para jóias de que fazia parte este fragmento guardava justamente objectos que iam compor o aspecto aprazível e sedutor do seu proprietário e assim, neste contexto, a exortação do texto da placa não podia ser mais propositada: «Faz o que o teu coração deseja!» O emotivo convite presente no cofre está em consonância com o apelo do canto: «Segue o teu coração.»

Trabalhado em fino baixo-relevo, o painel $164 \mathrm{D}$ mostra uma cena que evoca uma procissão de portadores de oferendas, vendo-se aqui um homem, com um pequena pêra no queixo, com duas faixas verdes que partem dos ombros e se cruzam no peito. Na cabeça tem um cesto pintado de verde, que segura com a sua mão direita aberta, cheio de frutos, indicados por sete pequenos círculos, saindo-lhe, sob o cesto, uma flor de lótus. Do braço esquerdo pende uma corda que suspende um cesto rectangular com frutos e na mão esquerda segura uma corda que prende um pequeno bovino.

O painel 164 E evoca também uma procissão de portadores de oferendas, que neste fragmento não se vêem, tendo por fundo uma decoração de papiros. O elemento central é uma flor de papiro alta, desenhada com 
minudência, pintada de verde, menos a base da corola de onde despontam os tufos. Está ladeada por dois botões de papiro fechados de cada lado, sendo dois maiores e dois mais pequenos.

O painel $164 \mathrm{~F}$ representa uma procissão de portadores de oferendas, que aqui não se vêem, tendo por fundo uma decoração de papiros. Vê-se no fragmento uma flor de papiro elevada que, tal como a anterior, devia ser ladeada por dois botões de lótus, mas um deles, o da direita, já desapareceu. A flor de papiro tem vestígios de cor verde, menos a corola de onde saem os tufos.

O painel $164 \mathrm{G}$ segue o mesmo tema, mas o fragmento está partido sensivelmente a meio, faltando a parte superior, vendo-se a terminação dos três caules de papiro. Uma figura masculina segura, junto à cintura, com a mão fazendo um delicado gesto, um pequeno cesto. A outra mão desaparecida segurava certamente um cesto à cabeça, sendo a imagem rematada, como noutros fragmentos, pelas corolas dos papiros abertas.

\section{LEÃo}

Bronze

Época Greco-Romana, início da dinastia ptolemaica (c. 300-250 a. C.)

Alt.: 5,4 cm; Comp.: 12,5 cm

Proveniência: Colecção MacGregor

Data de incorporação: 1922

$\mathrm{N}^{\mathrm{o}}$ inv.: 49

Leão em pose de marcha, em passo firme, com as patas e as orelhas sumariamente delineadas e os traços anatómicos da cabeça a revelar alguma acuidade de representação. Merece realce o pormenor da musculatura da pata anterior que vai juntar-se à farta juba do animal. Parte da pelagem está feita com

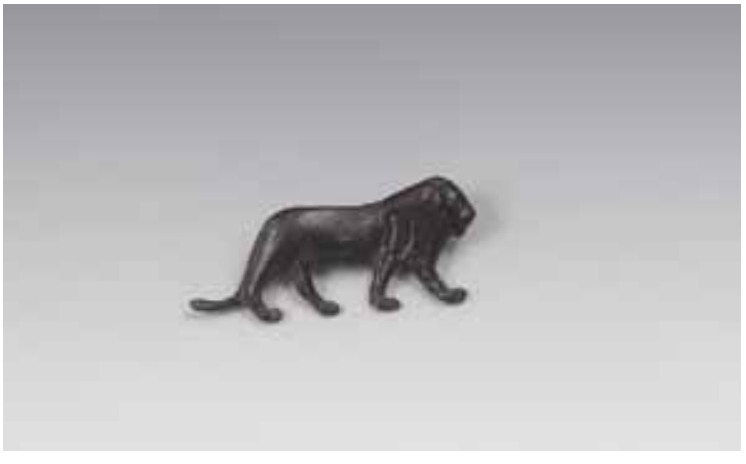

incisões. Atrás da figura existe um elemento para fixação da placa, a qual podia decorar uma peça de mobiliário.

Esta figura de bronze foi adquirida na venda da colecção do Dr. Fouquet, no Cairo, por intermédio da casa Graat e Madoulé, e fazia parte de um lote de peças achadas em escavações na área de Tell el-Muqdam, a antiga Leontópolis, onde se venerava o deus leonino Mahés, nome que pode ser traduzido como «Leão furioso», tendo os gregos reinterpretado o nome egípcio do deus como Miysis ou Mihos.

A peça ficou guardada na casa parisiense de Calouste Gulbenkian na Avenida de Iéna, até ser transferida para Portugal em 1958. Ela tinha antes uma base feita de grés, a qual foi retirada por Howard Carter a fim de facilitar a sua exposição numa vitrina da chamada «Sala Assíria» da casa de Gulbenkian.

\section{ESCARAVELHO}

Faiança

Época Baixa, XXVI dinastia (?)

Comp.: 0,35 cm; Larg.: 0,25 cm

Proveniência: Adquirido a Howard Carter

Data de incorporação: 1925

Escaravelho de faiança de cor turquesa, com os clípeos sumariamente tratados, protó- 
rax liso, élitros bem separados por um corte nítido e marcados por incisões, as patas assentando na base, que é ovalada. A base não tem inscrição e apresenta seis orifícios em redor para permitir a fixação do objecto, por cosedura, nas faixas de linho que envolviam a múmia ou em outros materiais fúnebres. Tem dois orifícios do lado esquerdo, outros dois do lado direito, um à frente e outro atrás.

Esta bonita peça foi adquirida directamente por Calouste Gulbenkian a Howard Carter, conservando-se desse acto o respectivo recibo de pagamento. Ficou guardada na casa parisiense do coleccionador, na Avenida de Iéna, numa vitrina da chamada «Sala Assíria», até ser transferida para Portugal em 1958, para dar entrada nas reservas sem nunca ter sido exposta.

\section{ESTATUETA FUNERÁRIA}

Faiança azul

Época Baixa, XXVI dinastia (?)

Alt.: 14,5 cm; Larg.: 4,2 cm

Proveniência: Desconhecida

Data de incorporação: Desconhecida

$\mathrm{N}^{\circ}$ inv.: 1048

Estatueta funerária conhecida pela designação de uchebti, de faiança azul e já sem o típico revestimento vidrado, assentando sobre uma pequena base medindo 3,5 x 3,2 $\mathrm{cm}$. O rosto mostra detalhes anatómicos gros[70 ] seiros, fazendo com que exprima um inusitado esgar que não é habitual neste tipo de representações. O rosto arredondado está envolvido por uma cabeleira tripartida onde as orelhas sobressaídas se inserem, caindo duas partes sobre o peito, a ladear a pêra entrançada que pende do queixo. Duas mãos cruzadas saem do envoltório fúnebre da estatueta, segurando os habituais utensílios da lavoura: na mão direita um alvião e uma corda que

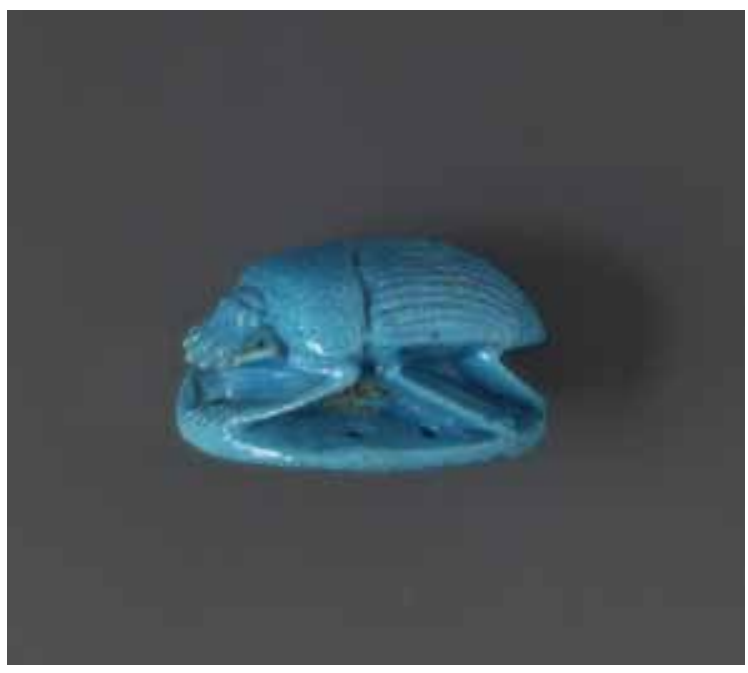

segura um saco de sementes que passa pelo ombro e cai atrás, e na esquerda um pequeno sacho. Na parte de trás a cabeleira é lisa, com um pequeno saco no ombro esquerdo, e tem um pilar dorsal onde foi gravado uma inscrição hieroglífica, com desajeitados signos e alguns ilegíveis, em duas colunas verticais, com uma incisão separadora ao meio.

Inscrição no pilar dorsal: «Ó uchebti (este), se for chamada a Osíris Padipepet, filha de Bastetirdis. Repara, aqui estou!» O texto que a estatueta apresenta é um pequeno extracto do capítulo 6 do «Livro dos Mortos», que se resume ao início e final do capítulo.

Não existe nos arquivos da colecção qualquer documento que indique a forma de aquisição deste uchebti. A verdade é que algumas casas de venda de antiguidades têm o hábito de oferecer, aos compradores de peças notáveis e caras, pequenos objectos à guisa de suplemento atencioso. Poderá ter sido este o caso da presente estatueta, e também da estatueta seguinte, das quais não há cópia de factura ou recibo. 
ESTATUETA FUNERÁRIA

Faiança azul

Época Baixa ou Época Greco-Romana

Alt.: $12 \mathrm{~cm}$; Larg.: 3,7 cm

Proveniência: Desconhecida

Data de incorporação: Desconhecida

$\mathrm{N}^{\circ}$ inv.: 1049

Estatueta funerária com uma cabeleira mais escura que o revestimento, à qual se pretendeu dar uma tonalidade de lápis-lázuli. Este uchebti anepígrafo assenta sobre uma base trapezoidal medindo $3 \times 2,4 \mathrm{~cm}$. Os traços do rosto estão feitos com algum detalhe, com pêra divina no queixo, e com as mãos cruzadas à frente sobre o peito. A mão direita segura um alvião e uma corda que cai sobre o ombro para suster o saco de sementes que cai para trás, e a mão esquerda empunha um sacho. Atrás tem um pilar dorsal, onde se adapta o corpo da figura, sem qualquer inscrição.

Não existe nos arquivos da colecção qualquer documento que indique a forma de aquisição desta estatueta funerária.

\section{Estatueta do deus osíris}

Bronze

Época Baixa (?)

Alt.: 15,6 cm; Larg.: 4,2 cm

Proveniência: Desconhecida

Data de incorporação: Desconhecida

$\mathrm{N}^{\mathrm{o}}$ inv.: 1050

Estatueta de bronze representando o deus Osíris, com a coroa atef, onde figura a serpente sagrada iaret (uaeus), ladeada por plumas, estando a da esquerda fracturada em cima e a da direita parcialmente desaparecida. Os traços do rosto foram feitos com algum detalhe e a pêra divina é entrelaçada. As mãos saem à frente do sudário, segurando dois ceptros. A da direita, em cima, exi- be o ceptro nekhakha, e a da esquerda, em baixo, o ceptro hekat, tendo ambos os ceptros incisões intervaladas a espaços regulares. Na base tem um pequeno espigão para fixação numa base que já desapareceu. Não existe nos arquivos da colecção qualquer documento que esclareça sobre o modo de aquisição desta peça.

\section{Estatueta do deus Harpócrates}

Bronze

Época Baixa (?)

Alt.: $11 \mathrm{~cm}$; Larg.: 2,6 cm

Proveniência: Desconhecida

Data de incorporação: Desconhecida

$\mathrm{N}^{\circ}$ inv.: 1047

Estatueta que representa o deus Harpócrates ou Hórus Criança, com a iconografia típica destas imagens juvenis: coroa dupla do Alto e do Baixo Egipto, de onde sai uma madeira de cabelo entrançada e espiralada que cai sobre o ombro direito. Os traços do rosto estão parcialmente erodidos mas percebem-se os detalhes anatómicos. O corpo está desnudado como é tradicional, com o braço esquerdo caído junto ao corpo e uma abertura entre o antebraço e o tronco, enquanto o braço direito flectido aproxima a mão da boca, com o dedo indicador apontado para os lábios. A perna esquerda está avançada sobre uma pequena base. Não existe nos arquivos da colecção qualquer documento que esclareça sobre o modo de aquisição desta peça.

\section{Estatueta de FUnCIONÁRIO}

Calcário

Império Antigo, VI dinastia (?)

Alt.: 46,5 cm; Larg.: 13,5 cm

Proveniência: Colecção Visconde

Rothermere

Data de incorporação: 1942

$\mathrm{N}^{\mathrm{o}}$ inv.: 2366 


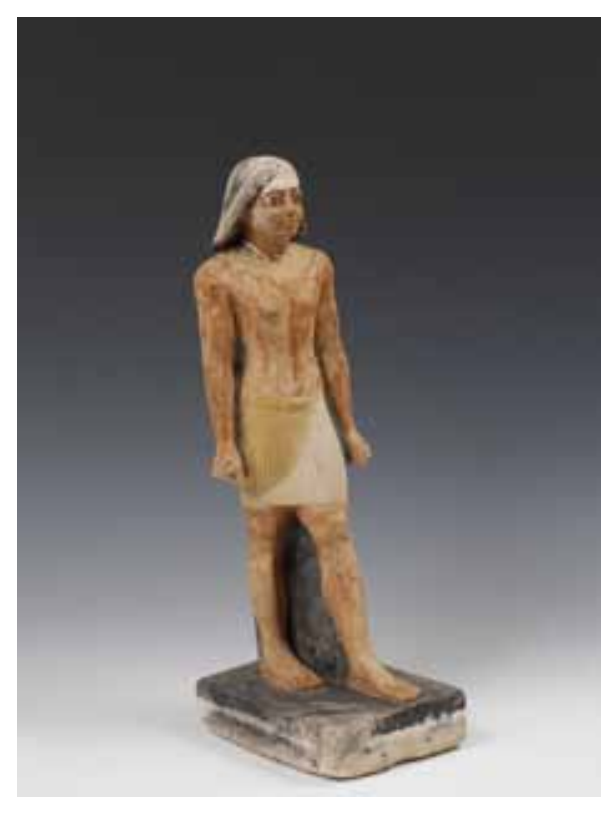

Estatueta que representa um homem em pose de marcha, com a perna esquerda avançada, sobre um pedestal que mede $4,5 \mathrm{~cm}$ de altura. A figura apresenta correctas proporções anatómicas e tem o corpo pintado numa tonalidade avermelhada. O cabelo tem risco ao meio e cai em leque sobre os ombros e o pilar atrás. Os traços do rosto estão bem delineados, com os olhos e as sobrancelhas pintadas de preto, exibindo um pequeno bigode também preto. Tem indícios de um colar pintado. Os braços caem ao longo do corpo, segurando nas mãos dois cilindros, sugerindo os símbolos de autoridade que, como é habitual, nunca se representam na totalidade, para evitar elementos sobressaídos na escultura. O saiote branco foi feito com algum esmero, com o plissado do tecido, que está cruzado à frente, e o fecho com cinto pintados de amarelo. Tem atrás um pilar estreito e descentrado. A estatueta foi adqurida na casa Sotheby's, Londres, no leilão da colecção egípcia do visconde Rothermere ( $\mathrm{n}^{\circ} 66$ do catálogo). A autenticidade desta peça foi posta em causa por William Smith, egiptólogo do Museu de Boston e professor de Arte Egípcia na Universidade de Harvard, em 1948. Apesar disso, esta estatueta acabou por ficar exposta, juntamente com outra da mesma época que a seguir se apresenta, na National Gallery of Art de Washington, entre 1949 e 1960, altura em que regressou a Lisboa. Em 1963, o Museu de Brooklyn, em Nova Iorque, solicitou à Fundação Calouste Gulbenkian a cedência da estatueta para que ela pudesse figurar numa exposição de objectos falsos, tendo a Fundação recusado, com a alegação de que não existiam provas da sua falsidade. A verdade é que na altura da sua aquisição por Calouste Gulbenkian, em 1942, a estatueta fora considerada autêntica por egiptólogos como Howard Carter (antes de 1939, ano em que ele faleceu) e Stephen Glanville. Christiane Desroches-Noblecourt, embora não o afirme claramente, acaba por manter as suas dúvidas sobre a autenticidade, numa carta enviada ao Museu datada de Maio de 1969. A questão pode actualmente resumir-se no seguinte: William Smith desconfiava da estatueta por a cabeleira não ter a cor correcta, por os lábios estarem pintados, e por a estatueta exibir certas manchas parecidas com ácido com que se costuma dar aos objectos uma aparência antiga. Christiane Desroches-Noblecourt acrescentava outros aspectos que para ela eram inesperados: uma moleza acentuada no rosto, a forma das sobrancelhas, a contracção da boca, a insipidez do olhar, as bochechas inchadas, a curva do nariz, a lisura da cabeleira, a pose do torso e a ligação dos braços ao tronco, o desajustado avanço da perna esquerda e a posição das mãos.

Curiosamente nenhum dos dois egiptólogos faz alusão ao desvio do pilar dorsal, que não está centrado ao meio como é habitual. O pilar dorsal apareceu em finais da IV dinastia mas a função inicial não era receber inscrições, isso ocorrerá mais tarde. 
ESTATUETA DE FUnCIONÁRIO

Calcário

Império Antigo, VI dinastia (?)

Alt.: $54 \mathrm{~cm}$; Larg.: 14,5 cm

Proveniência: Colecção Visconde Rothermere

Data de incorporação: 1942

$\mathrm{N}^{\circ}$ inv.: 2365

Estatueta que representa um homem em pose de marcha, com a perna esquerda avançada, sobre um pedestal que mede $7 \mathrm{~cm}$ de altura. A figura apresenta correctas proporcões anatómicas e tem o corpo pintado numa tonalidade avermelhada. O cabelo é curto e encrespado, pintado numa cor que agora parece púrpura, escondendo as orelhas. Os traços do rosto estão bem delineados, com os olhos e as sobrancelhas pintadas de preto. Os braços caem ao longo do corpo, segurando nas mãos dois cilindros, sugerindo os símbolos de autoridade que, como é habitual, nunca se representam na totalidade. para evitar elementos sobressaídos na escultura. O saiote branco foi feito com algum esmero, com o

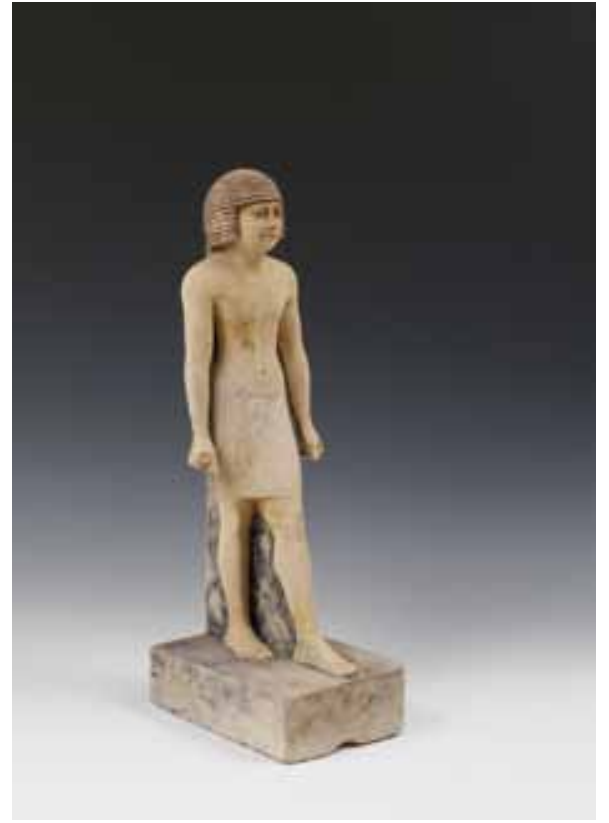

plissado do tecido, que está cruzado à frente, e o fecho com cinto pintados de amarelo. Tem atrás um pilar estreito e descentrado. A estatueta foi adqurida na casa Sotheby's, Londres, no leilão da colecção egípcia do visconde Rothermere ( ${ }^{\circ} 65$ do catálogo). 


\section{Bibliografia}

Affholder-Gérard, B.; Cornic, M.-J. 1990 Angers, Musée Pincé. Collections Égyptiennes. Paris / Angers.

Araújo, L.M. De

1993 Antiguidades Egípcias, I, Museu Nacional de Arqueologia. Lisboa

1994-1995 O núcleo egípcio da colecção Assis Ferreira, Cadmo 4/5: 75-94.

Assam, M.H.

1991 Arte Egípcia. Colecção Calouste Gulbenkian. Lisboa.

BÉNÉdite, G.

1924 Vraie ou fausse? Au sujet d'une statuette égyptienne, La Revue de l'Art XIV: 13-15.

BJÖRKMAN, G.

1971 A Selection of the Objects in the Smith Collection of Egyptian Antiquities at the Linköping Museum, Sweden. (Bibliotheca Ekmaniana 65). Estocolmo.

Bongionnni, A.; Croce, M. S. (Eds.)

2001 The Illustrated Guide to the Egyptian Museum in Cairo. Cairo.

EMERY, W.

1972 Archaic Egypt. Culture and Civilization in Egypt Five Thousand Years Ago. Harmondsworth.
MÁLeK, J:

1986 In the Shadow of the Pyramids. Egypt during the Old Kingdom. London.

Perdigão, J. de Azeredo

1979 Calouste Gulbenkian Coleccionador. Lisboa. s.a.

1965 Obras de Arte da Colecção Calouste Gulbenkian, Palácio Pombal. Oeiras.

SeIPEL, W.

1989 Ägypten. Götter, Gräber und die Kunst 4000 Jahre Jenseitsglaube. Linz.

SCHNEIDER, H. D.

1977 Shabtis. An introduction to the history of ancient egyptian funerary statuettes with a catalogue of the collection of shabtis in the National Museum of Antiquities at Leiden. Leiden, 3 vols.

Smith, S.; Edwards, I. E. S.

1937 Ancient Egyptian Sculpture Lent by C. S. Gulbenkian, Esq. London.

WALKER, J.; EdWARds, I. E. S.

1949 Egyptian Sculpture from the Gulbenkian Collection. Washington.

ZIEGLER, CH.

1987 Les arts du métal à la Troisième Période Intermédiaire, Tanis: L'Or des Pharaons. Paris: 85-101. 


\section{Trabajos de Egiptología Papers on Ancient Egypt}

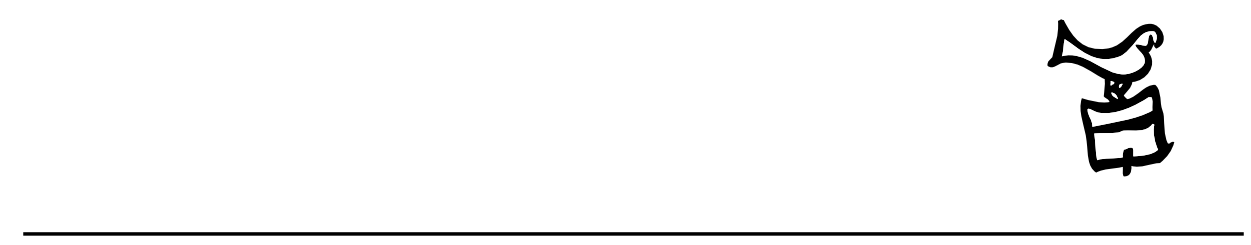

Número 5/1 2009 


\section{Actas \\ III Congreso Ibérico de Egiptología III Congresso Ibérico de Egiptologia}

Editores

Miguel Ángel Molinero Polo Covadonga Sevilla Cueva 


\title{
Editor
}

Miguel Ángel Molinero Polo

Universidad de La Laguna

\section{Consejo Editorial}

\author{
Antonio Pérez Largacha \\ Universidad de Castilla-La Mancha \\ José-R. Pérez-Accino \\ Birkbeck, Universidad de Londres \\ Covadonga Sevilla Cueva \\ Universidad Autónoma de Madrid
}

\section{Comité Científico}

Josep Cervelló i Autuori

Universitat Autònoma de Barcelona

$\mathrm{M}^{\mathrm{a}}$ José lópez Grande

Universidad Autónoma de Madrid

Josep Padró i Parcerisa

Universitat de Barcelona

$\mathrm{M}^{\mathrm{a}}$ Carmen Pérez Die

Museo Arqueológico Nacional, Madrid

Ester Pons Mellado

Museo Arqueológico Nacional, Madrid

José M. Serrano Delgado

Universidad de Sevilla

\section{Colaboradores Editoriales}

Linda Steynor

English editorial assistant

Hervé Mouriacoux

Assistant éditorial pour la langue française 
Trabajos de Egiptología está producida por Isfet. Egiptología e Historia c/ Blanco $1,2^{\circ}$

38400 Puerto de la Cruz

Tenerife-Islas Canarias

España

Maquetación: Proyecto Limón

(C) Autores de los artículos aparecidos

y Consejo Editorial de Trabajos de Egiptología - Papers on ancient Egypt

Depósito Legal: TF-2302-2009

ISSN: $1695-4750$

Imprime: Gráfica Los Majuelos, S.L.L.

imprenta@graficaslosmajuelos.com

Tfno.: 922311455 


\section{Comité Científico \\ III Congreso Ibérico de Egiptología III Congresso Ibérico de Egiptologia}

Miguel Á. Molinero Polo

Universidad de La Laguna

Presidente del Comité Organizador del III Congreso Ibérico de Egiptología

Miembro del Comité Organizador del I Encuentro de Egiptología

Josep Cervelló Autuori

Universitat Autònoma de Barcelona

Presidente del Comité Organizador del II Congreso Ibérico de Egiptologia

José Manuel Galán Allué

Consejo Superior de Investigaciones Cientificas

Director del Proyecto Djehuty, Luxor, Egipto

$\mathrm{M}^{\mathrm{a}}$ Helena Trindade Lopes

Universidad de Lisboa

Directora de la Misión Arqueológica Portuguesa en Menfis

Josep Padró i Parcerisa

Universitat de Barcelona

Director de la Misión Arqueológica de Oxirrinco

Antonio Pérez Largacha

Universidad de Castilla - La Mancha

Miembro del Comité Organizador del I Encuentro de Egiptología

José Ramón Pérez-Accino

Birkbeck College, University of London

Miembro del Comité Organizador del I Encuentro de Egiptología

$\mathrm{M}^{\mathrm{a}}$. Carmen Pérez Díe

Museo Arqueológico Nacional

Directora de la Misión Arqueológica Española en Heracleópolis Magna, Egipto

Covadonga Sevilla Cueva

Universidad Autónoma de Madrid

Miembro del Comité Organizador del I Encuentro de Egiptología 